\title{
Pablo Neruda: Soledad, Incomunicación e Individualismo en Memorial de Isla Negra
}

Memorial de Isla Negra es en el presente la obra más importante de Pablo Neruda - es su última gran colección de poemas - para evaluar su personalidad, sus sentimientos y su manera de pensar actuales. La obra de Neruda se ha caracterizado por sus continuos cambios estilísticos, que han correspondido a los cambios en la visión de! mundo del poeta. Esto ha sido sintetizado por Margarita Aguirre, quien comienza citando al propio Neruda:

He ido dejando atrás, who por uno, mis libros, susttuyendo, reconstruyendo cada vez más el sentido y la forma; soy el más grande adversario del nerudismo. ¿Cómo puede existir si yo termino con él en cada uno de mis libros?

Así decía Neruda hace algunos años con sobrada razón. Porque su obra va reflejando paso a paso su transformación humana, su camino de hombre abierto a los problemas de su tiempo. A la pasión adolescente de Crepusculario y Veinte poemas de amor sucede el crecer mediúmico de El hondero entusiasta y Tentativa del bombre infinito, que desemboca en el hermético ensimismamiento de Residencia en la tierra. Su extraordinaria fuerza vital, de acuerdo con el ritmo de su época, lo sacaría de ese pozo para llevarlo al tono épico del Canto general. Desde esa cumbre el poeta descubre la simplicidad que se conquista con los años y la experiencia. ${ }^{1}$

En el discurso de celebración de sus 50 años de edad, Neruda se ha referido a estos cambios: "Cambié muchas veces yo mismo. Cuando

1 Margarita Aguirte, Genio y Figura de Pablo Neruda, Editorial Universitaria de Buenos Aires, 2da. edición (Buenos Aires, 1967), p. 167. 
trato de recordar se superponen mis poemas, se confunden unos con otros, como cuando la hutuedad pega las hojas de los libros".2 Pero las referencias que Neruda hace a estos cambios son bien escasas hasta que aparece Memorial, ${ }^{3}$ donde el poeta menciona sus "cambios" muchas veces, o estos pueden detectarse fácilmente al comparar poemas que evocan distintos períodos de su vida. Algunos cambios que ocurrieron en el poeta joven que en aquel entonces carecía de la perspectiva adecuada, de la distancia objetivadora en el tiempo, se documentan ahora en $M e$. morial en poemas tales como "El primer mar", "El primer viaje", "El tren nocturno" y muchos otros. Memorial de Isla Negra es una recopilación de todos estos cambios, o sucesivas cosmovisiones del poeta. La técnica usada por Neruda en los tres primeros libros de esta obra (Donde nace la lluvia, La luna en el laberinto y El fuego cruel) es primordial. mente autobiográfica, y mayormente reflexiva en los dos últimos (El cazador de raices y Sonata crítica). Es ésta última la que más nos interesa aquí, pues con ella Neruda nos muestra su actual personalidad, personalidad que refleja el último "cambio" documentado por su poesía.

Para una comprensión adecuada tanto de los tres primeros libros co. mo de los dos últimos de Memorial es necesario tener en cuenta que en esta obra se yuxtaponen distintas visiones de la realidad del poeta. Esto produce en algunas ocasiones ciertas interferencias en cuanto al desarro. llo temático y "temporal" de un mismo poema. El poeta que escribe en el presente se refiere - en los primeros libros al menos - a hechos ocurridos en el pasado. Muchas veces el poeta no es otra cosa que un "observador", un simple narrador de anécdotas. Pero a veces reacciona ante los recuerdos que llegan a su memoria y entonces toma partido, mostrando una posición moral, social o política determinada. En otras palabras, los sentimientos que el poeta revive lo llevan a consideraciones que nada tienen que ver con su pasado. Pero lo esencial es que Neruda es un poeta con una nueva y más madura concepción del mundo, y entre anécdotas y recuerdos, compone poemas que definen su presente "ma. nera de ser", tendencia que va a dominar en $\mathrm{El}$ cazador de raices y en Sonata critica.

Para comprender la relativa complejidad de Memorial originada por esta multiplicidad de visiones de la realidad de Neruda, pormenoriza. remos los diferentes puntos de referencia desde los cuales son examinados su vida y pensamiento:

2 Emir Rodríguez Monegal, El viajero inmóvil, Editorial Losada, S. A. (Bue nos Aires, 1966), p. 46.

a En muchos casos abreviamos Memorial al referirnos a Memorial de lsla Negra, 
a. El Neruda de la infancia y la adolescencia tal como lo reconstruye el poeta actual por medio de su recuerdo.

b. El Neruda del pasado perteneciente a distintos períodos cronológicos, no sólo re-creado, sino evaluado por el presente poeta.

c. El Neruda actual.

d. Un poeta "constante" cuya condición de poeta es permanente e invariable a través de los diferentes períodos de su vida.

e. Un poeta acumulativo, un poeta que refleja la acumulación de todas sus "vidas" y de todas sus visiones poéticas.

En el primer libro de Memorial -Donde nace la lluvia-, Neruda evalúa poéticamente los orígenes de su existencia: la madre y el padre (las raíces biológicas); la madrastra (una raíz de amor y comprensión); el lugar de su nacimiento. La luna en el laberinto presenta dos temas principales: los primeros amores y los viajes. El fuego cruel representa la toma de conciencia política de Neruda, que comienza, según se documenta en este libro, con la Guerra Civil Española. Pero sin duda los dos últimos libros son los más importantes.

En El cazador de raices, "Cita de invierno", "Patagonias" y "Para la envidia" señalan una nueva tendencia en Memorial de Isla Negra. Con estos poemas Neruda inicia su "autorretrato", mostrando sus presentes sentimientos con respecto a los hombres y a la vida. Estos tres poemas son una especie de introducción a Sonata critica, donde dicha tendencia se observa en casi todos los poemas.

"Cita de invierno" es un largo poema dividido en siete partes que trata varios temas. Pero predomina aquí, tanto como en "Patagonias" y "Para la envidia", un tono general de desesperanza. La primera parte se refiere a la cita del poeta con la muerte (invierno) que ve aproximarse:

He esperado este invierno como ningún invierno se esperó por un hombre antes de mí, todos tenían citas con la dicha: sólo yo te esperaba, oscura hora.

$$
(M, \text { IV, p. } 47) *
$$

Esta "oscura hora" sin duda representa la muerte. Comparando el

4 Se cita de los textos originales de Memorial de Isla Negra publicados por: Editorial Losada, S. A. (Buenos Aires, 1964), en cinco volúmenes. En las citas para referirnos a Memorial de Isla Negra abreviamos $M$, indicamos el volumen de Memorial con un número romano y a continuación el número de la página en que aparece dicha cita. 
último verso transcrito con el penúltimo percibimos en la "oscura hora" una fuerte carga de tristeza, por contraste con las "citas con la dicha" que tienen otros hombres. Algunos versos más adelante Neruda hace una evocación más evidente de la muerte:

Es este invierno como el del año futuro, el de la inexistencia, con el frío total y la naturaleza no sabe que nos fuimos?

$$
\text { (M, IV, p. 47) }
$$

La muerte, rodeada de soledad, toma ahora la forma de la lluvia que en Donde nace la lluvia está íntimamente asociada a la muerte de su padre y su madrastra: ${ }^{5}$

No. Reclamé la soledad circundada

por un gran cinturón de pura lluvia

Tado estaba dispuesto para que llore el cielo.

El fecundo cielo de un sólo suave párpado dejó caer sus lágrimas como espadas glaciales y se cerró como una habitación de hotel el mundo: cielo lluvia y espacio.

$$
\text { (M, IV, p. 47) }
$$

El tema de la "soledad" va a repetirse mucho ahora en la poesía de Neruda. Esta soledad lo acompañará en su muerte y le dará un sentido de pureza que no puede encontrar ya en su relación con otros. En este

5 Las muertes del padre y la "mamadre" están presididas por la lluvia. En "El padre" leemos:

Un día con más lluvia que otros días el conductor José del Carmen Reyes subió al tren de la muerte y hasta ahora no ha vuelto.

$$
(M, I, p .27)
$$

"La mamadre" termina con los siguientes versos:

se fue, cumplida, oscura, al pequeño ataúd donde por primera vez estuvo ociosa bajo la dura lluvia de Temuco.

$$
(M, I, \text { p. 21) }
$$


momento Neruda es un hombre en su plenitud, un hombre que ha sido desgastado por los caminos de la vida y que ha aprendido todo lo que un hombre es capaz de aprender:

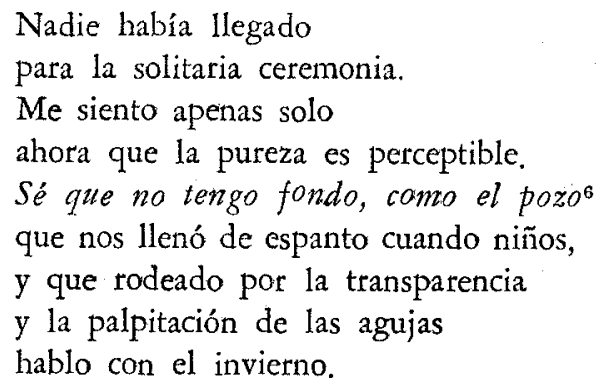

$$
(M, I V, \text { p. 48) }
$$

La visión de la soledad a la hora de la muerte aparece de nuevo en la cuarta parte del poema. Se refiere el poeta a un cambio que ha ocurrido en él, por el cual ha hallado su "verdadero". ser - su ser actual-, y declara que al fin ha logrado la posibilidad de esperar la muerte en soledad, un derecho que aunque triste ("este derecho triste", escribe), es algo nada más que (perdónesenos la redundancia) suyo:

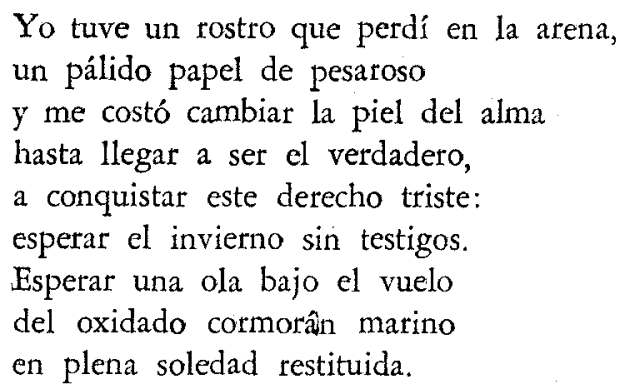

$$
(M, I V, \mathrm{pP} .49-50)
$$

Pero esta soledad que el poeta ahora reclama es el resultado de un problema más grave. Neruda es un hombre que siempre se ha "ofrecido" a los demás; siempre ha visto esta "entrega" como un deber, pero en este y en el siguiente libro de Memorial el poeta ve la invalidez de esta acción, porque nada ha recibido a cambio, excepto su propia sangre:

- El subrayado es nuestro. 
En "Para la envidia" se sintetiza esta idea. Creía que estaba cumpliendo un deber sagrado al of recer cuanto era suyo y ahora - en este preciso momento de su vida - comprende que no existe la reciprocidad:

y yo creí cumplir

creí que dando cuanto tenía, hiriéndome para no dormir, a todo sueño, a toda hora, a toda vida, con mi sangre $\mathrm{y}$ mis meditaciones

con lo que yo arranqué de una ola verde, o de una casa que dejó vacía la guerra, o de una lámpara que hallé encendida en medio del otoño

con todo y, más que todo, con lo que yo debía a cada hombre por su propia vida hice yo lo posible por pagar, y no tuve otra moneda que mi propia sangre.

$$
\text { (M, IV, p. 110-111) }
$$

Neruda no ve la solución al problema. El hombre es así y él no puede hacer nada por cambiarlo; quizá él simplemente ya no quiere bacer nada por cambiarlo. Es demasiado tarde para que pueda esperar nada de los "otros":

...Ahora

tal vez es tarde ya para encontrar

y volcar en la copa del rencor

la verdad atrasada y cristalina.

$$
\text { (M, IV, p. 111) }
$$

Neruda, de hecho, no muestra interés alguno en tratar de cambiar al hombre, Ha sido of̣endido, Es él (Neruda) el "ofendidọ" de los 
versos siguientes, quien se ha endurecido y no quiere volver a la "consagración de la ternura":

Tal vez el tiempo endureció la voz, la boca, la piedad del ofendido, y ya el reloj no podrá volver

a la consagración de la ternura.

$$
(M, I V, \text { p. 111) }
$$

Contra este odio y esta irreciprocidad para con él, el poeta tiene una única salida: retirarse del campo de batalla, aislarse de los hombres y la sociedad que ellos representan. Esto explica la necesidad de soledad expresada en los poemas anteriormente citados. Así, el poeta se aísla de los hombres, haciendo de su yo cordial un lugar de difícil acceso, porque se siente indefenso ante las debilidades de los hombres que tan profundamente lo afectan:

$Y$ no fue por orgullo que guardé

el corazón ausente de terror

Fue por otra razón, por indefenso.

$$
(M, I V, \text { p. 112) }
$$

En Sonata critica se pone de relieve todo esto en una forma más compleja. La irreciprocidad a que nos hemos referido lleva al aislamiento y éste produce una absoluta incomunicación entre los hombres y el poeta. Claro está que Neruda siente lo negativo de esta situación, pero vacila entre la aceptación de la misma - la soledad reclamada- y su rechazo. En 'Las comunicaciones", por ejemplo, se pronuncia por el rechazo de la soledad. Neruda decreta la muerte a los "subterráneos" que, opuestos a la "luz" evitan la "comunicación". En los "subterráneos" las caras están "cerradas" y los ojos no pueden ver. El poeta establece la comunión del hombre con el universo:

Muerte a los subterráneos: decreté.

Hasta cuando engañarse con la cara cerrada y ojos hacia no ver, hacia dormir, 
No es necesario nada sino ser

- y ser es a la luz, ser es ser visto

$y$ ver, ser es tocar, descubrir.

$$
\text { (M, V, p. 99) }
$$

La luz, ver y ser visto, tocar y descubrir, todo esto es ser. Los sub. terráneos son el no ser. El presente Neruda toma conciencia del verdadero valor de la existencia del hombre (su propia existencia en este caso). Antes decía en el cuarto libro de Memorial, "Al bosque mío entro con raíces". Ahora las raíces no son suficientes. La flor es también igualmente importante. La raíz es inútil a menos que pueda producir belleza:

Abajo todo el que no tiene flor!

De nada sirven sólo las raíces!

$$
\text { (M, V, p. 99) }
$$

Por último, intentando una identificación con los hombres, escribe:

somos con otros hombres y mujeres:

a plena luz amamos,

a pleno amor nos ven y eso nos gusta:

sin silencio es la vida verdadera.

Sólo la muerte se quedó callada.

$$
\text { (M, V, p. 100) }
$$

Pero todo esto es lo que el poeta quisiera que ocurriese, no lo que ocurre en realidad; o sea, el poeta quisiera que otras condiciones hiciesen posible esta comunicación de que escribe. El verso "sin silencio es la vida verdadera", donde establece que la verdadera vida debe estar asociada con el sonido, estaría en contradicción con otras declaraciones de Memorial, a menos que veamos, como hemos señalado, en los versos anteriores, una situación puramente ideal. La triste verdad, sin embargo, de un poeta que quiere escapar la cruda realidad, se presenta en "La noche":

Quiero no saber ni soñar.

Quién puede enseñarme a no ser, a vivir sin seguir viviendo?

$$
\text { (M, V, p. 13) }
$$


Quiere aisiarse de todo lo que represente vida, al extremo de desear ser invisible:
Alguna vez ser invisible
hablar sin palabras, oir
sólo ciertas gotas de lluvia, sólo el vuelo de cierta sombra.

$$
(M, \mathrm{~V}, \mathrm{p}, 13)
$$

Hay un poema dedicado aquí íntegramente a este tema: "La soledad". El poeta permanece solo no simplemente porque él lo quiera sino, también, porque otros hombres no se le acercan. El poeta, como hemos anotado, se ofrece, pero no hay reciprocidad del resto de la humanidad. Aquí es necesario relacionar los conflictos de este Neruda con los conflictos de otro poeta con quien Neruda se identifica profundamente en los dos últimos libros de Memorial: nos referimos a César Vallejo. Hay varios temas repetidos a lo largo de los dos últimos libros más importantes de Vallejo (Trilce y Poemas humanos): la limitación del hombre, el aislamiento, la soledad y la irreciprocidad de otros hombres, que están presentes también en El cazador de raíces y Sonata crítica. En relación con la "irreciprocidad" de otros hombres Neruda escribe en "La soledad":

Lo que no pasó fue tan súbito que allí me quedé para siempre sin saber, sin que me supieran, como debajo de un sillón, como perdido en la noche

$$
\text { (M, V, p. 29) }
$$

La misma idea es expresada por Vallejo en "Trilce XLIX":

Nadie me busca ni me reconoce, y hasta yo he olvidado

de quien seré

En los bastidores donde nos vestimos, no hay, no Hay nadie: hojas tan sólo

$$
\text { de par en par. }{ }^{7}
$$

7 César Vallejo, Trilce, Edición Perú-Nuevo (Lima, 1961), pp. 85-86. 
El hombre es visto por ambos, el presente Neruda y Vallejo, como un ser impasible y de rutina, despreocupado de la existencia de su prójimo y aún de la suya propia. El hombre es para Vallejo poco mấs que un animal:

que es lóbrego mamífero y se peina...

$y$, sujeto a tenderse como objeto, se hace buen carpintero, suda, mata y luego canta, almuerza, se abotona.. .

Neruda presenta a este mismo hombre que, ignorando al poeta, no contesta las preguntas que le hace: hombres, mujeres - la humanidad en general-, se oponen a cualquier tipo de comunicación entre ellos y el poeta. Estos hombres y mujeres, como el hombre de Vallejo, ignoran al poeta preocupándose únicamente de su propia "subsistencia". Neruda escribe:

Pregunté a los otros después, a las mujeres, a los hombres, qué hacian con tanta certeza y cómo aprendieron la vida: en realidad no contestaron, siguieron bailando y viviendo.

$$
\text { (M, V, p. 29) }
$$

Neruda al principio trata de explicarse la razón de esta conducta, pero cuando comprende que ésta es una actitud "común", algo cambia dentro de él:

Es lo que no le pasó a uno

lo que determina el silencio,

y no quiero seguir hablando

porque allí me quedé esperancio:

en esa región y aquel día

no sé lo que me pasó

pero ya yo no soy el mismo.

$$
\text { (M, V, p. 29) }
$$

8 César Vallejo, Poemas bumanos (1923-1938); Espania, aparta de mí este cá. liz (1937-1938), Editorial Losada, S. A. (Buenos Aires, 1961), pp. 37-38. 
La soledad llega ahora al poeta como algo natural: nada tiene que hacer para encontrarla, concepto expresado en "No es necesario":

$$
\begin{aligned}
& \text { No es necesario silbar. } \\
& \text { para estar solo, } \\
& \text { para vivir a oscuras. }
\end{aligned}
$$

$$
\text { (M, V, p. 59) }
$$

Nadie recuerda ni comprende al poeta, por tanto se convierte él en el único testigo de sí mismo:

En plena muchedumbre, a pleno cielo, nos recordamos a nosotros mismcs, al intimo, al desnudo, al único que sabe cómo crecen sus uñas, que sabe cómo se hace su silencio y sus pobres palabras.

$$
\text { (M, V, p. 59) }
$$

Consecuentemente se refugia en los límites de sí mismo, la única vía que le queda para hallar su auténtico ser:

regresamos al pétalo escondido, al hueso, a la raíz semi secreta y alli, de pronto, somos, somos aquello puro y olvidado, somos lo verdadero entre los cuatro muros de nuestra única piel, entre las dos espadas de vivir y morir.

$$
\text { (M, V, pp. 59-60) }
$$

Sólo en los límites de si mismo puede encontrar "lo verdadero". Su propio cuerpo marca los límites de sus relaciones con otros hombres ("entre los cuatro muros de nuestra única piel"), y la vida y la muerte marcan los límites de la existencia del poeta.

Como el poeta sabe que no encontrará otra cosa que incomunicación y soledad, trata de crear, poéticamente, otro universo, u otro mundo donde pueda existir una relación armónica entre el poeta y los hombres; pero el resultado es un fracaso absoluto. Todo esto está expresado en 
"El futuro es espacio". El futuro da al poeta todas las posibilidades; el futuro es ambiguo. En este futuro Neruda prevé un amor comunal y armónico ("hay lugar para todos en el bosque") opuesto al amor "desesperado" que ha quedado atrás:

Atrás quedó el amor desesperado que no tenía sitio para un beso, hay lugar para todos en el bosque,

$$
\text { (M, V, p. 109) }
$$

Sigue en el poema un toque de ironía. Se encuentra un nuevo planeta y el poeta llega allí con un teléfono (el teléfono es el símbolo de la comunicación par excellence). Pero "el hombre" lo echa todo a perder al hablar solamente de sus enfermedades, debilidad que repre. senta su imperfección, su limitación. El hombre es, pues, un elemento destructor de toda armonía:

$$
\begin{aligned}
& \text { qué placer es hallar por fin, } \\
& \text { un plabiendo } \\
& \text { grandes estrellas claras como el vodka } \\
& \text { tan transparentes y deshabitadas, } \\
& \text { y alli llegar con el primer teléfono } \\
& \text { para que hablen más tarde tantos hombres } \\
& \text { de sus enfermedades. }
\end{aligned}
$$

$$
\text { (M, V, p. 109) }
$$

Lo único que el poeta puede hacer de nuevo es aislarse. La soledad vuelve a ser su único refugio. Los hombres son para él un "río sofocante" que tiene que abandonar $y$ del cual tiene que huir:

Adelante, salgamos

del río sofocante

en que con otros peces navegamos

desde el alba a la noche migratoria

$y$ ahora en este espacio descubierto volemos a la pura soledad.

$$
(M, \mathrm{~V}, \mathrm{p}, 110)
$$


Es evidente que el poeta no se refiere solamente a él, pues en tal caso hubiera usado el singulat y no el plural volemos o salgamos. En este momento Neruda probablemente se refiere a alguien que compartirá su futuro con él: Matilde Urrutia. Se alude a ella en la estrofa anterior a la transcrita atriba:

Lo importante es apenas divisarse, gritar desde una dura cordillera $y$ ver en la otra punta los pies de una mujer recién llegada.

$$
(M, \mathrm{~V}, \mathrm{pp} \cdot 109-110)
$$

No es una coincidencia que el poema siguiente de Sonata Critica sea "Amores: Matilde". Neruda concluye que la soledad es el único modo que tiene de sobrevivir, de "existir", pero es una soledad en la cual él no estará completamente solo: Matilde estará con él, ambos formando una sola entidad - de amor-, lejos de los demás hombres y lejos de ese "río sofocante" que los dos abandonan.

Neruda así, paso a paso, nos va haciendo confesiones a lo largo de estos dos últimos libros de Memorial de Isla Negra, y podemos con relativa facilidad ir reconstruyendo su personalidad, muy conflictiva, de hoy. No sólo se atreve Neruda a hablarnos de su, en definitiva, voluntaria soledad, de la imperfección del hombre y de su irreciprocidad, sino que toca un tema que es muchísimo más delicado: su actitud política. El poema "La verdad" es fundamental en este respecto. El poeta hace un recuento, una verdadera "integración" de sus ideas y afirma que ama el "realismo" y el "idealismo" por igual:

$$
\begin{aligned}
& \text { Os amo idealismo y realismo, } \\
& \text { como agua y piedra } \\
& \text { sois } \\
& \text { parte del mundo, } \\
& \text { luz y raíz del árbol de la vida. }
\end{aligned}
$$

$$
(M, V, \text { p. 103) }
$$

Idealismo y realismo no son para él cosas opuestas, y así abraza un idealismo que contradice la filosofía materialista del partido al cual pertenece. Aunque sabe que esto no es $l o$ que debería ser; es sin embargo lo que él quiere: 
Sé que no puede ser, pero esto quise.

Amo lo que no tiene sino sueños.

Tengo un jardín de flores que no existen.

Soy decididamente triangular.

$$
(M, V, \text { p. 103) }
$$

Su idealismo está expresado por el verso "Amo lo que no tiene sino sueños"; las flores son parte de este sueño ("Tengo un jardín de flores que no existen"). La referencia al triangulo es significativa. El triangulo, tiene una forma problemática, en relación con el cuadrudo perfecto o el limpio rectángulo. En Fin de mundo, uno de sus libros recicntes, Neruda hace precisamente una alusión al rectángulo como figura geométrica de perfección ideal:

Otra vez Ibamos recién resurrectos buscando otra vez la ambrosía, buscando la vida lineal, la limpieza de los rectángulos, la geometría $\sin$ recodos: ${ }^{9}$

El poeta es "triangular: ninguno de sus lados tiene otro que le corresponda, él es "una geometría con recodos". El poeta obviamente afirma su individualismo.

Pareceria estar a punto de claudicar ante los "dogmas" del partido:

No puedo más con la razón al hombro.

Quiero inventar el mar de cada día.

$$
\text { (M, V, p. 104) }
$$

Neruda incluye una anécdota sobre un pintor "realista". Con el mismo tono humorístico de su Estravagario, hace alli la crítica de todo lo que se interpone en el camino de la libertad del artista:

Vino una vez a verme un gran pintor que pintaba soldados. Todos eran heroicos y el buen hombre los pintaba en el campo de batalla muriéndose de gusto.

- Pablo Neruda, Fin de mundo, Editorial Losada, S. A., 2da. edición (Buenos Aires, 1970, P. 23. 
También pintaba vacas realistas

$y$ eran tan extremadamente vacas

que uno se iba poniendo melancólico

y dispuesto a rumiar eternamente.

$$
(M, V, \text { p. 104) }
$$

En el mismo tono sarcástico, Neruda manifiesta su desprecio por el "realismo socialista":

Execración y horror! Lei novelas

interminablemente bondadosas

y tantos versos sobre el Primero de Mayo

que ahora escribo sólo sobre el 2 de ese mes.

$$
(M, V, \text { p. 104) }
$$

Los "slogans" y la "propaganda" provocan en él una reacción similar:

Parece ser que el hombre

atropella el paisaje

y ya la carretera que antes tenía cielo

ahora nos agobia

con su empecinamiento comercial.

$$
(M, V, \text { p. 104) }
$$

"La carretera que antes tenía cielo" - ideas que tenían todo un cielo abierto a mil posibilidades - se convierte en una carga ("ahora nos agobia"). Como esta carretera, la belleza también se "comercializa". Esto, como es lógico, puede ocurrir lo mismo en el capitalismo que en el socialismo; cualquiera que sea el caso, Neruda se opone a la "limitación" de una belleza dictada por determinadas estructuras económicas o políticas:

Así suele pasar con la belleza como si no quisiéramos comprarla

y la empaquetan a su gusto y modo.

Hay que dejar que baile la belleza con los galanes más inaceptables, entre el día y la noche: 
no la obliguemos a tomar la píldora de la verdad como una medicina.

$$
(M, V, p, 105)
$$

Todo está bien claro. La belleza, el arte, la poesía, tienen que apar. tarse de toda preconcepción social o encasillamiento político. Una vez que la belleza toma "la píldora de la verdad", una vez que la hacemos dirigirse a un fin extra-artístico preconcebido (político, social, etc.), deja de ser arte o belleza para convertirse en otro producto "comercializado" y "utilitario". Este es sin duda uno de los poemas más antidogmáticos de todo Memorial. El arte de Neruda no está muy lejos, por otra parte, de la observación "real" del universo, aunque como escribe al principio del poema, ha tratado de armonizar idealismo y realismo. Está de parte de lo real cuando la realidad se presente como una dimensión espiritual:

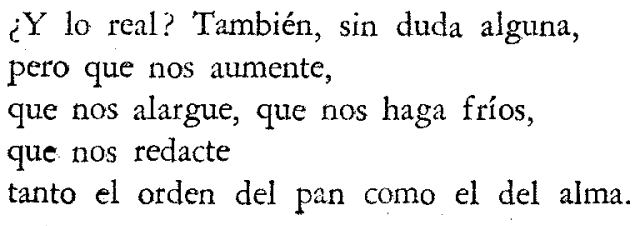

$$
(M, V, p \cdot 105)
$$

La conclusión del poema es una confesión que define al presente Neruda:

No soy rector de nada, no dirijo, y por eso atesoro

las equivocaciones de mi canto.

$$
(M, V, \text { p. 105) }
$$

El poeta, como la belleza misma - que para ser belleza tiene que moverse entre varias realidades-, vacila también, "se equivoca" tal como confiesa. Pero precisamente por ser poeta (creador de belleza), tiene que atesorar las "equivocaciones de su canto": estas equivocaciones son formas de belleza que ningún compromiso social o político puede hurtarle. El Neruda que encontramos aquí no es el poeta engagé que escribió Canto general, Las uvas y el viento, Canción de gesta, etc.; estamos presenciando la última visión poética de Neruda. Claro está que no rechazará de golpe las convicciones sociales de toda una vida, pero el poeta 
ahora va a oscilar entre una poesía "comprometida" un poco a la fuerza y una poesía absolutamente lírica, subjetivísima. En Fin de mundo vamos a encontrar poemas aún de fuerte contenido social ("III_Por qué señor; En Cuba", "IX.—Coloniando" y otros: de hecho, predomina en el libro el aspecto social), ${ }^{10}$ mientras que sus dos libros más tecientes, La espada encendida y Las piedras del cielo ${ }^{12}$ se inclinan abiertamente al otro lado - són libros de un profundo subjetivismo. Es necesatio señalar, sin embargo, que Memorial de Isla Negra sigue siendo hasta 1973 la obra más compleja y valiosa de la producción poética reciente de Pablo Neruda, y la única que nos permite hacer, como hemos intentado aunque parcialmente, una evaluación de la actual personalidad del poeta.

\section{LuIs F. GoNzÁlez-Cruz}

Pemsylvania State University at New Kensington

10 Pablo Neruda, Fin de mundo, Buenos Aires: Editorial Losada, S. A., 2 da. edición 1970. III, pp. 43-55; IX, Pp. 142-155.

11 pablo Neruda, La espada encendida, Buenos Aires: Editorial Losada, S. A. 1970 . 1970.

Pable Neruda, Las piedras del cielo, Buenos Aires: Editorial Losada, S. A., 
